\title{
Spindle cell morphology is related to poor prognosis in vulvar squamous cell carcinoma
}

\author{
M D Trietsch ${ }^{*}{ }_{1}$, A A W Peters ${ }^{2}$, K N Gaarenstroom ${ }^{2}$, S H L van Koningsbrugge ${ }^{1}$, N T ter Haar ${ }^{1}$, E M Osse ${ }^{1}$, \\ N Halbesma ${ }^{3}$ and G J Fleuren ${ }^{1}$ \\ ${ }^{1}$ Department of Pathology, Leiden University Medical Center, PO Box 9600, 2300 RC Leiden, The Netherlands; ${ }^{2}$ Department of \\ Gynaecology, Leiden University Medical Center, PO Box 9600, 2300 RC Leiden, The Netherlands and ${ }^{3}$ Department of Clinical \\ Epidemiology, Leiden University Medical Center, PO Box 9600, 2300 RC Leiden, The Netherlands
}

\begin{abstract}
Background: Vulvar cancer is the fourth most common gynaecological malignancy, with an annual incidence of 2 out of 100000 women. Although most cases of early stage vulvar cancer have a good prognosis, recurrence and rapid tumour progression can occur. We investigated the prevalence of spindle cell morphology in vulvar cancer and its association with survival.

Methods: This retrospective cohort study included 108 patients with primary vulvar squamous cell carcinoma who were treated at the Leiden University Medical Center during 2000-2009. Paraffin-embedded tissue was examined for the presence of spindle cell morphology. Survival and histology data were compared between cases with spindle and without spindle cell morphology.

Results: Twenty-two (20\%) tumours showed spindle cells infiltrating the stromal tissue. All spindle cell tumours were human papillomavirus (HPV) negative. Spindle cell morphology was strongly associated with poor prognosis and with a high risk of lymph node involvement at the time of diagnosis (relative risk 2.26 (95\% $\mathrm{Cl} 1.47-3.47)$ ). Five-year disease-specific survival was lower in patients with vs without spindle cell morphology (45.2\% vs 79.7\%, respectively; $P=0.00057)$.
\end{abstract}

Conclusion: Vulvar spindle cell morphology occurs frequently and seems to develop through the non-HPV pathway. It is associated with a worse prognosis than conventional vulvar squamous cell carcinoma.

Vulvar cancer is the fourth most common gynaecological malignancy in developed countries with an incidence of approximately 2 cases per 100000 women each year (Sturgeon et al, 1992; Sankaranarayanan and Ferlay, 2006; Dittmer et al, 2011). This cancer is mostly seen in post-menopausal women, and the average age at diagnosis is 70 years. Nearly $90 \%$ of all vulvar carcinomas are vulvar squamous cell carcinoma (VSCC) (Hacker, 2005). Squamous cell carcinomas of the vulva can be divided into two aetiological types (van der Avoort et al, 2006; Carless and Griffiths, 2008). The first type is seen mainly in younger patients and is associated with human papillomavirus (HPV) infection (van de Nieuwenhof et al, 2008). The second type is seen mostly in elderly patients and seems to develop independent of HPV infection. This type of carcinoma is associated with lichen sclerosis and mutations of the TP53 gene (van der Avoort et al, 2006; van de Nieuwenhof et al, 2008).
Vulvar carcinoma generally has a good prognosis when detected and treated at an early stage, but the most common treatment modalities, that is, surgical removal and/or radiotherapy, can be mutilating and have high morbidity rates (Ansink and van der Avoort, 2000; Gaarenstroom et al, 2003; de Hullu and van der Zee, 2006). A small proportion of patients suffer from early recurrence, rapid progression of tumour growth and death (van der Zee et al, 2008). Identifying risk factors for poor survival is important to further reduce the mortality and morbidity of vulvar cancer patients, but few studies have found new factors of clinical importance (Knopp et al, 2009). To date, lymph node involvement is the only accurate prognostic factor for survival and recurrence (Oonk et al, 2006).

A specific histological type of squamous cell carcinoma, termed spindle cell carcinoma, is seen occasionally. Spindle cell carcinoma is also referred to as pseudosarcoma or carcinosarcoma.

*Correspondence: Dr MD Trietsch; E-mail: m.d.trietsch@lumc.nl

Received 5 July 2013; revised 20 August 2013; accepted 22 August 2013; published online 24 September 2013 
Spindle cells are thin, slender, elongated cancer cells that infiltrate stromal tissue and that occur either as single cells or as cords of cells rather than as groups or islands (Figure 1). Spindle cell carcinoma is seen in many different types of cancer and is associated with a worse prognosis in cancers of the oral cavity, oesophagus and lung (Santeusanio et al, 1991; Ahluwalia et al, 1996; Minami et al, 2008; Pelosi et al, 2010; Travis, 2010). Spindle-shaped epithelial cancer cells have lost their typical epithelial characteristics and seem to gain the ability to infiltrate the underlying stroma and metastasize (Kalluri and Weinberg, 2009).

Spindle cell carcinomas consisting of spindle cells alone have been reported only incidentally in vulvar carcinoma, and it is thought to be an aggressive tumour type that occurs in $1-5 \%$ of all VSCC patients (Steeper et al, 1983; Santeusanio et al, 1991; Cockayne et al, 1998; Cooper et al, 2002; Santos-Briz et al, 2002; Choi et al, 2006; Petrillo et al, 2011; Terada, 2011). Some VSCCs show a specific pattern of invasion in which there is infiltration of the stroma by single cells or cords of tumour cells adjacent to the 'conventional' squamous cell carcinoma cells. This pattern is also called 'spray pattern invasion'. This spray pattern invasion is seen more often than the rare vulvar spindle cell carcinoma and has been described before (Crissman and Azoury, 1981; Hacker et al, 1983; Drew et al, 1996). A subpopulation of these vulvar carcinomas with a spray pattern of invasion clearly shows areas of infiltrating cells that resemble spindle cell carcinoma. We suggest that these tumours be termed 'vulvar squamous cell carcinomas with spindle cell morphology' and describe the criteria used to characterise these tumours in the Materials and Methods section. The characteristics of tumours with this pattern of invasion and their association with survival have, to our knowledge, not been studied in a large cohort of patients. We hypothesize that tumours with spindle cell morphology, that is, tumours consisting of both 'conventional' squamous cell carcinoma cells and spindle cells, may share some of the aetiology and clinical behaviour with the aggressive spindle cell carcinomas. We considered whether spindle cell morphology is a possible risk factor and studied its prevalence and possible relation with prognosis.

\section{MATERIALS AND METHODS}

Patients. All patients who were primarily surgically treated for primary VSCC between 2000 and 2009 at the Leiden University Medical Center, a referral centre for gynaecological cancers in The Netherlands, were considered for inclusion in this study.

Clinical and follow-up data were retrieved from patient medical records and from the cancer registration database. Patients were excluded if they had received systemic immunosuppressive therapy, chemotherapy or radiotherapy in the pelvic area before surgery. Tumour staging was performed according to the FIGO system using histologically confirmed TNM data. We used the 1995 staging instead of the revised 2009 staging because of the
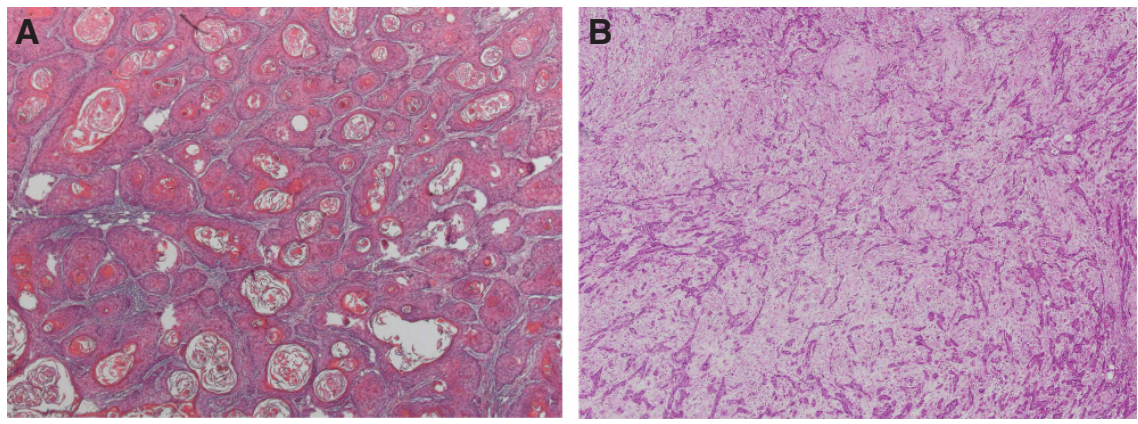

Figure 1. Representative images of (A) vulvar squamous cell carcinoma and (B) vulvar squamous cell carcinoma with spindle cell morphology ( $\times 20$ magnification).
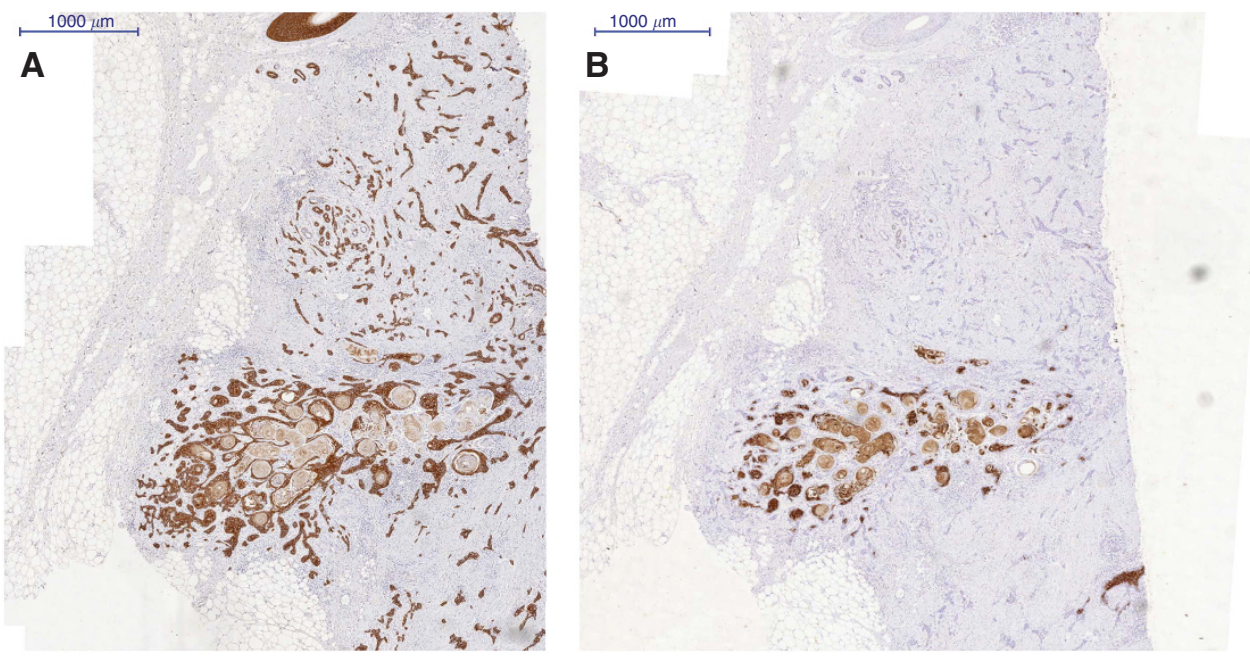

Figure 2. A representative image of a sample of vulvar squamous cell carcinoma with spindle cell morphology stained for (A) keratin 14 and (B) keratin 10. Note that the spindle-shaped cells are positive for keratin 14 but negative for keratin 10, while the solid component of the tumour is positive for both keratins 14 and 10 (Bar $=1000 \mu \mathrm{m})$. 
retrospective design of the study (Creasman, 1995; Pecorelli, 2009). The patients were followed up until December 2012. Patient samples were handled according to the medical ethical guidelines described in the Code of Conduct for Proper Secondary Use of Human Tissue of the Dutch Federation of Biomedical Scientific Societies.

Microscopy and immunohistochemistry. All formalin-fixed, paraffin-embedded tissue blocks from the selected primary VSCC patients that were stored in the Leiden University Medical Center archives were examined microscopically for the presence of spindle-shaped tumour cells on haematoxylin and eosin-stained slides. Tumours from which only biopsies were taken were excluded from the study.

One series of consecutive $4-\mu \mathrm{m}$ paraffin-embedded tissue sections was taken from all tumour-containing tissue blocks and stained as described previously (Schrevel et al, 2011) using primary antibodies for pankeratin AE1AE3 (mAB 3412, 1:2000, Millipore, Billerica, MA, USA), keratin 10 (DE-k10, 1:50, DAKO, Glostrup, Denmark) and keratin 14 (LL002, 1:2000, Abcam, Cambridge, UK). All slides were digitalised using a Mirax slide scanner and analysed using Panoramic Viewer (version 1.15.50, 3DHistec, Budapest, Hungary).

As there is no established definition of spindle cell morphology, we categorised the samples as follows. Tumour cells were categorised as spindle cells if they had an elongated shape, infiltrated the underlying stromal tissue as single cells or as cords of cells instead of as islands of cells and were keratin 14-positive and keratin 10-negative as markers of dedifferentiation (Figure 2). When at least 10 spindle cells were seen per high power field using a $40 \times 0.65$ objective, independent of the proportion of spindle cells in relation to the solid component of the cancer, the tumour was categorised as having spindle cell morphology. Spindle-shaped cells in close proximity $(<0.5 \mathrm{~mm})$ to the solid component of the tumour were not marked as spindle cell carcinoma cells but were considered to be a part of the spray pattern invasive border of the solid tumour.

HPV analysis. DNA extracted from formalin-fixed, paraffinembedded tumour tissue was used for HPV-type analysis. To prevent and check for contamination, sections of a paraffin block without tissue, which were cut before each tumour sample, served as negative controls. All such controls were negative in the PCR analysis. The INNO-LiPA HPV Genotyping Extra Amp kit (Innogenetics, Gent, Belgium) for in vitro diagnostic use, which is a highly sensitive hybridisation assay, was used for HPV typing as described previously (Vermeulen et al, 2007). This assay is able to detect oncogenic and common HPV types (Vermeulen et al, 2007).

Statistical analysis. Statistical analyses were conducted using the IBM SPSS Statistics software package (version 20, IBM-SPSS Statistics, Armonk, NY, USA). The independent $t$-test was used to compare baseline variables, and the Fisher's exact test was used to analyse categorical and normally distributed numerical data. The Shapiro-Wilk test was used to test for normality. The Mann-Whitney $U$ test was used for data with a skewed distribution. Kaplan-Meier curves, the log rank test and Cox's Proportional Hazard regression analysis were performed to analyse the differences in survival between the spindle and non-spindle groups. A $P$-value $\leqslant 0.05$ was considered significant, corresponding to $95 \%$ confidence intervals. All tests were two-tailed. Results for normally distributed numerical data are presented as mean with standard deviation (s.d.), and results for skewed numerical data are presented as median with interquartile range (IQR).

Disease-free survival was defined as survival from the date of surgery until the first recurrence or death or until the end of study follow-up. The overall survival of the patients was measured from the date of surgery until death from any cause or until the end of study follow-up. Disease-specific survival was measured from the date of surgery until death from vulvar cancer or until the end of study follow-up. Recurrent disease in the vulvar area was characterised as 'local recurrence', whereas recurrences in the inguinal region were characterised as 'regional recurrence'. Recurrent disease on the contralateral side of the vulva was considered to be a second primary tumour.

\section{RESULTS}

Between January 2000 and December 2009, 129 patients were treated surgically for primary VSCC at the Leiden University Medical Center. Nine patients were excluded, because they had a history of chemotherapy, pelvic radiotherapy or immunosuppres-

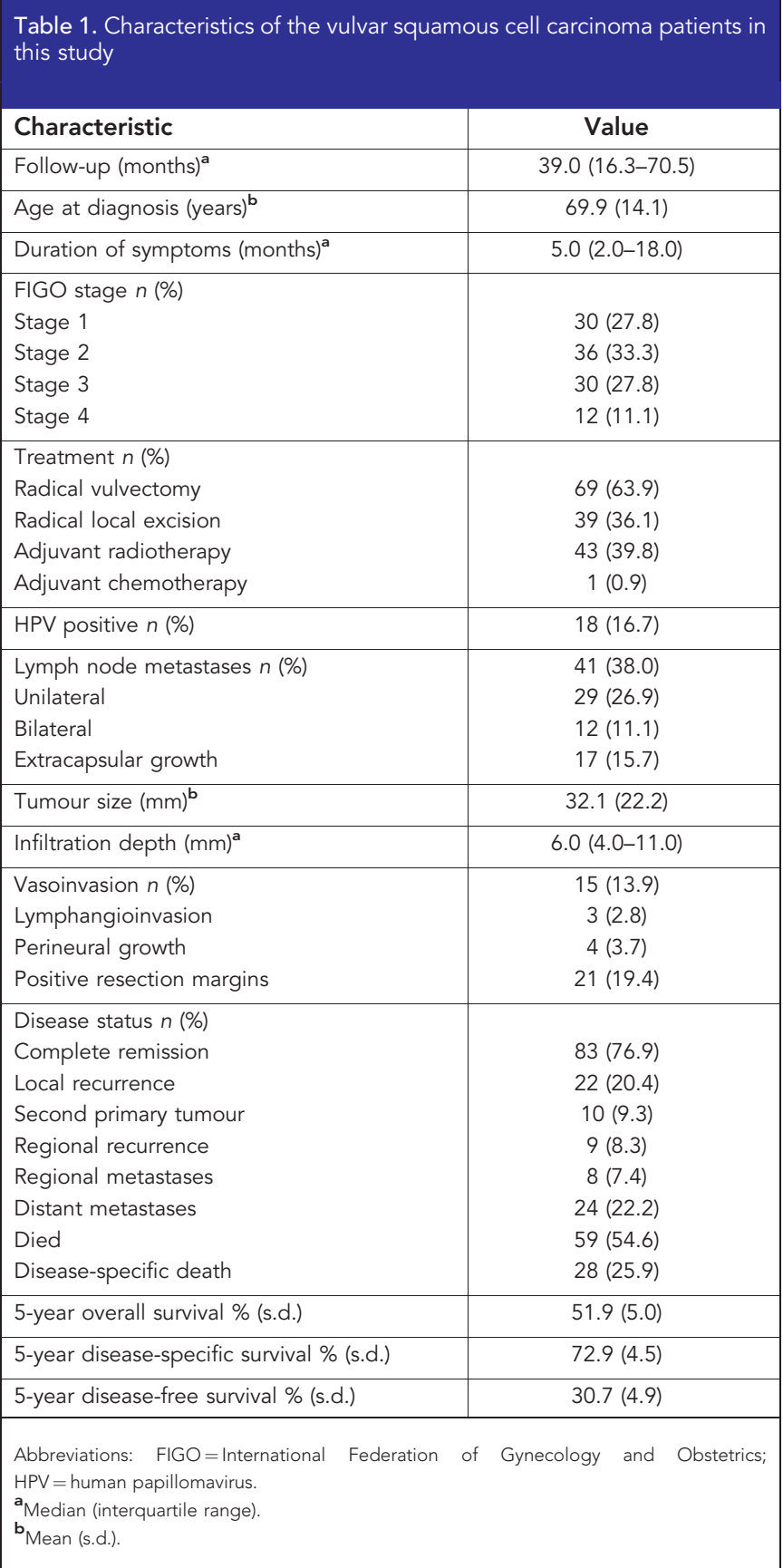


sive therapy for vulvar cancer or for another disease before the current diagnosis. Eleven patients were excluded, because their tumours were biopsied, but no further surgical treatment was given. Tumour tissue from one patient was of poor quality and was not analysed further. Thus, a total of 108 patients with primary VSCC met all of our inclusion criteria. Table 1 lists the characteristics of these patients.

The median follow-up time was 39 months (IQR 16.3-70.5), and the mean age at diagnosis with vulvar carcinoma was 69.9 years (s.d. 14.1). Symptoms first occurred at a median of 5.0 months (IQR 2.0-18.0) before diagnosis. Microscopic evaluation showed a mean tumour size of $32.1 \mathrm{~mm}$ (s.d. 22.2) and a median infiltration depth of $6.0 \mathrm{~mm}$ (IQR 4.0-11.0). Lymph node metastases were found in 41 of the 108 patients $(38.0 \%)$. Thirty patients $(27.8 \%)$ had a tumour that was FIGO stage 1,36 patients (33.9\%) stage 2, $30(27.8 \%)$ stage 3 and $12(11.1 \%)$ stage 4 . Forty-three patients $(39.8 \%)$ received adjuvant radiotherapy to the groin and/or vulva; 38 of these patients received adjuvant radiotherapy, because they were stage 3 or higher, and 5 of them received it because a tumour-free resection margin of $<8 \mathrm{~mm}$ was obtained. One patient received adjuvant radiotherapy and chemotherapy because of close tumour-free resection margins plus the presence of multiple inguinal lymph node metastases.

At the end point of the study period, $20 \%$ of the patients had developed local recurrent disease and $26 \%$ had died from the disease, giving a 5 -year disease-free survival of $31 \%$ (s.d. 4.9) and a 5 -year disease-specific survival of $73 \%$ (s.d. 4.5).

Comparison of the clinical outcomes for patients with spindle and non-spindle cell morphology. Of the 108 tumours that were analysed, 22 tumours (20\%) were identified as having spindle cell morphology and $86(80 \%)$ as being non-spindle cell carcinomas. Table 2 summarises the outcome measurements for patients with

Table 2. Comparison of the clinical outcomes for patients with spindle and non-spindle cell morphology

\begin{tabular}{|c|c|c|c|}
\hline Outcome & Spindle $n=22(20.4 \%)$ & Non-spindle $n=86(79.6 \%)$ & $\boldsymbol{P}$-value \\
\hline Follow-up (months) ${ }^{a}$ & $18.0(8.8-46.0)$ & $48.0(123.0-77.5)$ & $0.026^{b}$ \\
\hline Age at diagnosis (years) & $71.0(13.2)$ & $69.7(14.4)$ & 0.617 \\
\hline Duration of symptoms (months) ${ }^{a}$ & $4.0(2.8-12.5)$ & $5.0(2.0-22.0)$ & 0.951 \\
\hline $\begin{array}{l}\text { FIGO stage } n(\%) \\
\text { Stage } 1 \\
\text { Stage } 2 \\
\text { Stage } 3 \\
\text { Stage } 4\end{array}$ & $\begin{array}{l}3(13.6) \\
4(18.2) \\
8(36.4) \\
7(31.8)\end{array}$ & $\begin{array}{c}27(31.4) \\
32(37.2) \\
22(25.6) \\
5(5.8)\end{array}$ & $0.002^{b}$ \\
\hline $\begin{array}{l}\text { Treatment } n \text { (\%) } \\
\text { Radical vulvectomy } \\
\text { Radical local excision } \\
\text { Adjuvant radiotherapy } \\
\text { Adjuvant chemotherapy }\end{array}$ & $\begin{array}{c}14(63.6) \\
8(36.4) \\
14(63.6) \\
(0.0)\end{array}$ & $\begin{aligned} 55 & (64.0) \\
31 & (36.0) \\
29 & (33.7) \\
1 & (1.2)\end{aligned}$ & $\begin{array}{l}1.000 \\
0.020^{b}\end{array}$ \\
\hline HPV positive $n(\%)$ & $(0.0)$ & $18(20.9)$ & $0.011^{\mathrm{b}}$ \\
\hline $\begin{array}{l}\text { Lymph node metastases } n(\%) \\
\text { Unilateral } \\
\text { Bilateral } \\
\text { Extracapsular growth }\end{array}$ & $\begin{array}{l}15(68.2) \\
8(36.4) \\
7(31.8) \\
8(36.4)\end{array}$ & $\begin{array}{c}26(30.2) \\
21(24.4) \\
5(5.8) \\
9(10.5)\end{array}$ & $\begin{array}{l}0.002^{b} \\
0.001^{b} \\
0.006^{b}\end{array}$ \\
\hline Tumour size $(\mathrm{mm})^{c}$ & $38.7(21.4)$ & $30.5(22.2)$ & 0.610 \\
\hline Infiltration depth $(\mathrm{mm})^{a}$ & $8.0(4.5-12.0)$ & $6.0(3.0-11.0)$ & 0.242 \\
\hline $\begin{array}{l}\text { Vasoinvasion } n(\%) \\
\text { Lymfangioinvasion } \\
\text { Perineural growth } \\
\text { Positive resection margins }\end{array}$ & $\begin{array}{c}6(27.3) \\
1(4.6) \\
1(4.6) \\
7(31.8)\end{array}$ & $\begin{aligned} 9 & (8.3) \\
2 & (2.3) \\
3 & (3.5) \\
14 & (16.3)\end{aligned}$ & $\begin{array}{l}0.077 \\
0.499 \\
1.000 \\
0.131\end{array}$ \\
\hline $\begin{array}{l}\text { Disease status } n(\%) \\
\text { Complete remission } \\
\text { Local recurrence } \\
\text { Second primary tumour } \\
\text { Regional recurrence } \\
\text { Regional metastases } \\
\text { Distant metastases } \\
\text { Died } \\
\text { Disease-specific death }\end{array}$ & $\begin{array}{c}11(50.0) \\
5(22.7) \\
2(9.1) \\
2(9.1) \\
1(4.5) \\
7(31.8) \\
18(81.8) \\
11(50.0)\end{array}$ & $\begin{aligned} 72 & (83.7) \\
17 & (19.8) \\
8 & (9.3) \\
7 & (8.1) \\
7 & (8.1) \\
17 & (19.8) \\
41 & (47.7) \\
17 & (19.8)\end{aligned}$ & $\begin{array}{l}0.003^{b} \\
0.771 \\
1.000 \\
1.000 \\
0.443 \\
0.007^{b} \\
0.002^{b}\end{array}$ \\
\hline 5-year overall survival \% (s.d.) & $27.3(9.5)$ & $58.2(5.6)$ & $0.00041^{b}$ \\
\hline 5-year disease-specific survival \% (s.d.) & $45.2(11.4)$ & $79.7(4.6)$ & $0.00057^{b}$ \\
\hline 5-year disease-free survival \% (s.d.) & $25.0(12.5)$ & $44.3(6.6)$ & 0.149 \\
\hline \multicolumn{4}{|c|}{$\begin{array}{l}\text { Abbreviations: } F I G O=\text { International Federation of Gynecology and Obstetrics; } H P V=\text { human papillomavirus. } \\
{ }^{a} \text { Median (interquartile range). } \\
\text { b }_{\text {Significant difference }(P<0.05)} \\
{ }^{c} \text { Mean (s.d.). }\end{array}$} \\
\hline
\end{tabular}


carcinomas with spindle cell and non-spindle cell morphology. The mean age did not differ between the two groups. Vulvar spindle cell carcinoma patients were diagnosed at a higher FIGO stage than non-spindle patients, though the duration of symptoms before diagnosis did not differ.

Forty-one of the 108 patients had lymph node metastases at the time of diagnosis, 15 of which were also positive for spindle cells. This gives a relative risk of lymph node metastasis in spindle cell morphology patients of 2.26 (95\% CI 1.47-3.47) compared with patients without spindle cell morphology. Eighteen of 108 patients tested positive for HPV (type $16(n=10), 18(n=2)$ or $33(n=5)$; one patient tested positive for both HPV types 16 and 33). None of these patients had carcinomas with spindle cell morphology.

Compared with spindle cell morphology patients, more nonspindle patients achieved complete remission $(83.7 \%$ vs $50.0 \%$, $P=0.003$ ). At the end point of the study period, $22.7 \%$ of the spindle cell morphology patients and $19.8 \%$ of the non-spindle cell patients had developed local recurrent disease, and $9.1 \%$ and $8.1 \%$ of patients, respectively, developed regional recurrences $(P=1.000)$. In terms of disease-specific death, $50 \%$ of the spindle cell patients and $19.8 \%$ of the non-spindle cell patients died from the disease $(P=0.002)$.

Overall survival differed significantly between patients with and without vulvar spindle cell morphology (Figure 3A), with a 5-year overall survival of $27.3 \%$ (s.d. 9.5) vs $58.2 \%$ (s.d. 5.6; $P=0.00041$ ), respectively. Disease-specific survival was significantly worse for spindle cell morphology patients than for non-spindle cell morphology patients, with a 5 -year disease-specific survival of $45.2 \%$ (s.d. 11.4) vs $79.7 \%$ (s.d. 4.6; $P=0.00057$; Figure 3B). Five-year disease-free survival did not differ significantly between the two groups $(25.0 \%$ vs $44.3 \%, P=0.149)$.

Univariate Cox regression analysis for disease-specific death resulted in a hazard ratio of $3.50(95 \%$ CI $1.63-7.52, P=0.001)$ for spindle cell morphology patients compared with non-spindle cell patients. After correction for the possible confounders age and HPV infection, the hazard ratio became 2.71 (95\% CI 1.26-5.81, $P=0.011)$. When correcting for more tumour characteristics (tumour size, infiltration depth, positive resection margins), vulvar spindle cell morphology patients had a hazard ratio for disease-specific death of 2.51 (95\% CI 1.12-5.64). Adding lymph node metastasis and regional or distant metastasis to the correction model gave a hazard ratio of 4.1 (95\% CI 1.61-10.60) for patients with carcinomas with spindle cell morphology (Table 3).

A

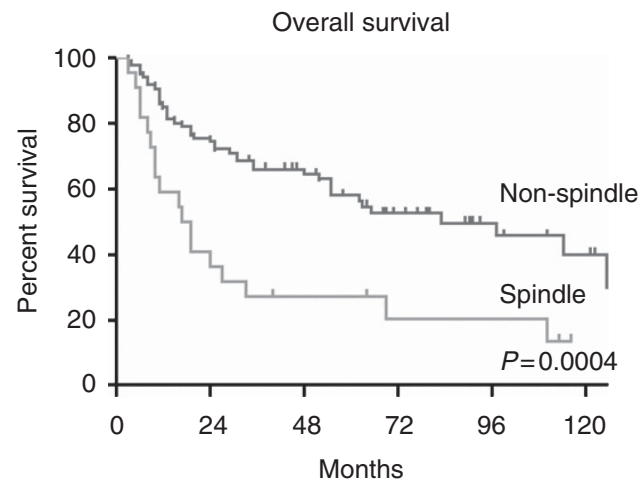

B

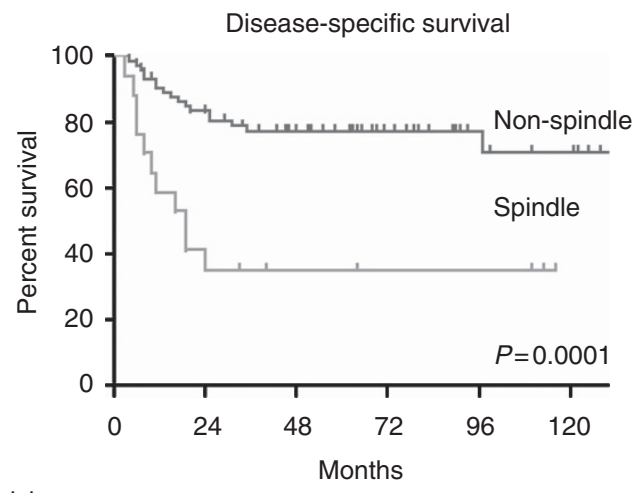

\begin{tabular}{lcccccc} 
N At risk & & \multicolumn{7}{c}{ Months } \\
Non-spindle & 86 & 57 & 31 & 16 & 9 & 4 \\
Spindle & 22 & 7 & 5 & 3 & 1 & 0
\end{tabular}

\begin{tabular}{lcccccc} 
N At risk & & \multicolumn{7}{c}{ (3) } \\
Non-spindle & 86 & 64 & 43 & 23 & 13 & 7 \\
Spindle & 22 & 8 & 5 & 3 & 3 & 0
\end{tabular}

\section{DISCUSSION}

This study is, to our knowledge, the first to investigate vulvar spindle cell morphology in a large group of patients with VSCC. Spindle cell morphology occurred frequently in our series and was found in $20 \%$ of the VSCCs examined. Carcinoma with spindle cell morphology has not been reported as a separate entity in vulvar cancer before this report. A spray pattern of invasion, which also includes spindle cell morphology, has been reported in a few papers (Crissman and Azoury, 1981; Hacker et al, 1983; Drew et al, 1996) and was found in 11 out of 26 VSCCs by Drew et al (1996). In the latter study, which was relatively small, a spray pattern of invasion was significantly associated with poor survival after correction for FIGO stage alone.

Our study of a large cohort of VSCC patients shows that patients with spindle cell morphology have a worse prognosis than patients with conventional squamous cell carcinoma of the vulva. The disease-specific and overall survival was almost half that of non-spindle squamous cell carcinoma patients. After correcting for multiple possible confounders, vulvar spindle cell morphology remains an independent prognostic factor. None of the patients with spindle cell morphology showed HPV infection, strongly suggesting that these tumours arise through the non-HPV pathway (van der Avoort et al, 2006; Ueda et al, 2011).

The vulvar spindle cell morphology patients reported having symptoms for a similar length of time before diagnosis than nonspindle cell patients, but VSCC patients presented with higher FIGO stages, possibly because of the aggressive character of spindle cells and the rapid progression of this type of tumour.

Although this series is the largest reported in the literature, the number of patients in this study is still too small to correct for all potential confounders. However, even after correcting for multiple tumour characteristics that are likely to be part of the causal path (tumour size, infiltration depth, positive resection margins, lymph node metastasis and distant metastasis), vulvar spindle cell morphology patients had a hazard ratio for disease-specific death of 4.14 (95\% CI 1.61-10.60) relative to non-spindle cell patients, suggesting that the poor prognosis of these patients is associated with spindle cell morphology and is independent of other tumour characteristics. Caution has to be taken when interpreting multivariate analysis in small cohorts of patients. Given the distinct differences in survival, we suggest that this retrospective study be replicated at other large institutions to determine the added prognostic value of spindle cell morphology in a prognostic model.

Figure 3. (A) Overall survival and (B) disease-specific survival in the 108 vulvar squamous cell carcinoma patients in this study. There were significant differences in both overall and disease-specific survival for patients who had carcinomas with vs without spindle cell morphology (relative risk of dying 1.7 vs $2.5 ; 95 \% \mathrm{Cls} 1.3-2.3$ and $1.4-4.6 ; P=0.0043$ and $P=0.0041$, respectively). 


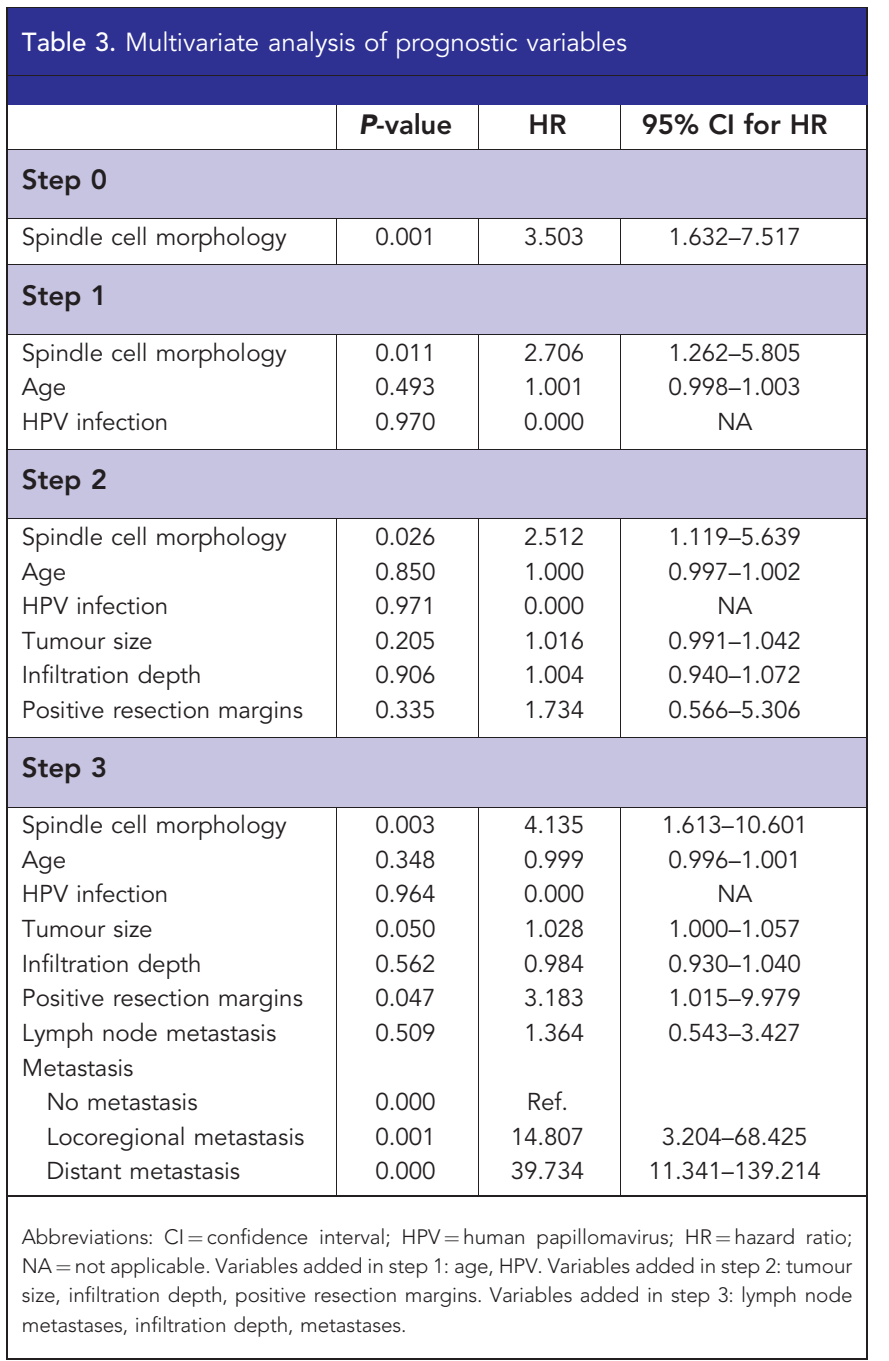

Regarding the survival and overall incidence of spindle cells, selection bias could have been introduced by our inclusion of patients who were treated primarily by surgery. Patients who were treated by excision biopsy alone were not selected for this series, and such patients usually have smaller tumours and a better prognosis. On the other hand, patients with inoperable tumours, and likely a worse prognosis, were also not selected, so patient selection cannot fully explain the differences in survival. Notably, correcting for tumour size did not change the finding that spindle cell morphology patients have a significantly worse prognosis.

These results may have implications for the clinical management of VSCC. Spindle cells can be detected by a trained pathologist and, if necessary, be visualised using commonly available keratin stains. Given our finding that spindle cell morphology does not affect the risk of local recurrent disease, the current advice to perform a local radical tumour resection with 8-mm tumour-free margins after fixation seems appropriate (de Hullu and van der Zee, 2006). However, the increased risk of lymph node metastasis and poorer prognosis could influence the choice to perform adjuvant chemotherapy or radiotherapy in vulvar spindle cell morphology patients.

\section{CONCLUSION}

VSCC with spindle cell morphology appears to be an aggressive tumour type. In this series of patients, this cancer type had a worse prognosis than conventional VSCC as well as an increased risk of lymph node metastases at the time of diagnosis.

\section{CONFLICT OF INTEREST}

The authors declare no conflict of interest.

\section{REFERENCES}

Ahluwalia H, Gupta SC, Gupta SC (1996) Pathology in focus. Spindle-cell carcinoma of the nasal septum. J Laryngol Otol 110(3): 284-287.

Ansink A, van der Avoort I (2000) Surgical interventions for early squamous cell carcinoma of the vulva. Cochrane Database Syst Rev (2): CD002036.

Carless MA, Griffiths LR (2008) Cytogenetics of melanoma and nonmelanoma skin cancer. Adv Exp Med Biol 624: 227-240.

Choi DS, Lee JW, Lee SJ, Choi CH, Kim TJ, Lee JH, Bae DS, Ahn G, Kim BG (2006) Squamous cell carcinoma with sarcomatoid features of the vulva: a case report and review of literature. Gynecol Oncol 103(1): 363-367.

Cockayne SE, Shah M, Slater DN, Harrington CI (1998) Spindle and pseudoglandular squamous cell carcinoma arising in lichen sclerosus of the vulva. Br J Dermatol 138(4): 695-697.

Cooper WA, Valmadre S, Russell P (2002) Sarcomatoid squamous cell carcinoma of the vulva. Pathology 34(2): 197-199.

Creasman WT (1995) New gynecologic cancer staging. Gynecol Oncol 58(2): 157-158.

Crissman JD, Azoury RS (1981) Microinvasive carcinoma of the vulva. A report of two cases with regional lymph node metastasis. Diagn Gynecol Obstet 3(1): 75-80.

de Hullu JA, van der Zee AG (2006) Surgery and radiotherapy in vulvar cancer. Crit Rev Oncol Hematol 60(1): 38-58.

Dittmer C, Katalinic A, Mundhenke C, Thill M, Fischer D (2011) Epidemiology of vulvar and vaginal cancer in Germany. Arch Gynecol Obstet 284(1): 169-174.

Drew PA, al-Abbadi MA, Orlando CA, Hendricks JB, Kubilis PS, Wilkinson EJ (1996) Prognostic factors in carcinoma of the vulva: a clinicopathologic and DNA flow cytometric study. Int J Gynecol Pathol 15(3): 235-241.

Gaarenstroom KN, Kenter GG, Trimbos JB, Agous I, Amant F, Peters AA, Vergote I (2003) Postoperative complications after vulvectomy and inguinofemoral lymphadenectomy using separate groin incisions. Int J Gynecol Cancer 13(4): 522-527.

Hacker NF (2005) Vulvar cancer. In Practical Gynecologic Oncology, Berek JS, Hacker NF (eds). pp 543-576. Lippincott Williams \& Wilkins: Philadelphia, PA, USA.

Hacker NF, Berek JS, Lagasse LD, Nieberg RK (1983) Microinvasive carcinoma of the vulva. Obstet Gynecol 62(1): 134-135.

Kalluri R, Weinberg RA (2009) The basics of epithelial-mesenchymal transition. J Clin Invest 119(6): 1420-1428.

Knopp S, Trope C, Nesland JM, Holm R (2009) A review of molecular pathological markers in vulvar carcinoma: lack of application in clinical practice. J Clin Pathol 62(3): 212-218.

Minami SB, Shinden S, Yamashita T (2008) Spindle cell carcinoma of the palatine tonsil: report of a diagnostic pitfall and literature review. Am J Otolaryngol 29(2): 123-125.

Oonk MH, Hollema H, de Hullu JA, van der Zee AG (2006) Prediction of lymph node metastases in vulvar cancer: a review. Int $J$ Gynecol Cancer 16(3): 963-971.

Pecorelli S (2009) Revised FIGO staging for carcinoma of the vulva, cervix, and endometrium. Int J Gynaecol Obstet 105(2): 103-104.

Pelosi G, Sonzogni A, De PT, Galetta D, Veronesi G, Spaggiari L, Manzotti M, Fumagalli C, Bresaola E, Nappi O, Viale G, Rosai J (2010) Review article: pulmonary sarcomatoid carcinomas: a practical overview. Int J Surg Pathol 18(2): 103-120.

Petrillo M, Corrado G, Carbone A, Macchia G, Ferrandina G (2011) Vulvar squamous cell carcinoma with sarcoma-like stroma: a case report and review of the literature. Diagn Pathol 6: 95.

Sankaranarayanan R, Ferlay J (2006) Worldwide burden of gynaecological cancer: the size of the problem. Best Pract Res Clin Obstet Gynaecol 20(2): $207-225$.

Santeusanio G, Schiaroli S, Anemona L, Sesti F, Valli E, Piccione E, Spagnoli LG (1991) Carcinoma of the vulva with sarcomatoid features: a case report with immunohistochemical study. Gynecol Oncol 40(2): 160-163. 
Santos-Briz A, Antunez P, Lopez-Rios F, Rodriguez-Peralto JL, Garzon A (2002) Human papillomavirus-negative spindle cell carcinoma of the vulva associated with lichen sclerosus: case report and literature review. Am J Dermatopathol 24(2): 135-138.

Schrevel M, Gorter A, Kolkman-Uljee SM, Trimbos JB, Fleuren GJ, Jordanova ES (2011) Molecular mechanisms of epidermal growth factor receptor overexpression in patients with cervical cancer. Mod Pathol 24(5): $720-728$.

Steeper TA, Piscioli F, Rosai J (1983) Squamous cell carcinoma with sarcomalike stroma of the female genital tract. Clinicopathologic study of four cases. Cancer 52(5): 890-898.

Sturgeon SR, Brinton LA, Devesa SS, Kurman RJ (1992) In situ and invasive vulvar cancer incidence trends (1973 to 1987). Am J Obstet Gynecol 166(5): 1482-1485.

Terada T (2011) Sarcomatoid squamous cell carcinoma of the vulva expressing smooth muscle actin and S100 protein. Arch Gynecol Obstet 283(5): 1103-1106.

Travis WD (2010) Sarcomatoid neoplasms of the lung and pleura. Arch Pathol Lab Med 134(11): 1645-1658.

Ueda Y, Enomoto T, Kimura T, Yoshino K, Fujita M, Kimura T (2011) Two distinct pathways to development of squamous cell carcinoma of the vulva. J Skin Cancer 2011: 951250. van de Nieuwenhof HP, van der Avoort IA, de Hullu JA (2008) Review of squamous premalignant vulvar lesions. Crit Rev Oncol Hematol 68(2): 131-156.

van der Avoort IA, Shirango H, Hoevenaars BM, Grefte JM, de Hullu JA, de Wilde PC, Bulten J, Melchers WJ, Massuger LF (2006) Vulvar squamous cell carcinoma is a multifactorial disease following two separate and independent pathways. Int J Gynecol Pathol 25(1): 22-29.

van der Zee AG, Oonk MH, de Hullu JA, Ansink AC, Vergote I, Verheijen RH, Maggioni A, Gaarenstroom KN, Baldwin PJ, Van Dorst EB, Van der Velden J, Hermans RH, van der Putten H, Drouin P, Schneider A, Sluiter WJ (2008) Sentinel node dissection is safe in the treatment of early-stage vulvar cancer. J Clin Oncol 26(6): 884-889.

Vermeulen CF, Jordanova ES, Szuhai K, Kolkman-Uljee S, Vrede MA, Peters AA, Schuuring E, Fleuren GJ (2007) Physical status of multiple human papillomavirus genotypes in flow-sorted cervical cancer cells. Cancer Genet Cytogenet 175(2): 132-137.

(c) (i) (2) (2) This work is licensed under the Creative Commons (c) Attribution-NonCommercial-Share Alike 3.0 Unported License. To view a copy of this license, visit http://creativecommons. org/licenses/by-nc-sa/3.0/ 